Short Communication

\title{
EVALATION OF RELATIONSHIP BETWEEN MARKERS OF LIVER FUNCTION AND THE ONSET OF TYPE 2 DIABETES
}

\author{
Raiza Philip ${ }^{1}$, Michelle Mathias ${ }^{2}$, Suchetha Kumari N. ${ }^{3}$, \\ Damodara Gowda K.M. ${ }^{4} \&$ Jayaprakash Shetty K. ${ }^{5}$ \\ ${ }^{1} \mathrm{M}$ BBS Student (II year), ${ }^{2}$ Additional Professor, ${ }^{5}$ Professor \& HOD, Department of Pathology, ${ }^{3}$ Professor, \\ Department of Biochemistry, ${ }^{4}$ Assisstant Professor, Department of Physiology, K.S. Hegde M edical Academy, \\ Nitte University, Deralakatte, M angalore - 575 018, Karnataka, India. \\ Correspondence : \\ Raiza Philip \\ M BBS Student (II year), K.S. Hegde M edical Academy, Nitte University \\ Deralakatte, Mangalore - 575 018, Karnataka, India. \\ E-mail : raiza12794@gmail.com
}

\begin{abstract}
:
Background and Objective: Type 2 diabetic individuals are highly prone to liver function test abnormalities than non-diabetic individuals. Increased activities of liver enzymes such as aspartate aminotransferase (AST), alanine aminotransferase (ALT), and ?glutamyl transpeptidase (GGT) are indicators of hepatocellular injury. Increased activity of these markers is associated with insulin resistance [1], metabolic syndrome, and type 2 diabetes. Diabetes mellitus burden is one of the key concerns in developing countries like India. In this study, we evaluated the relationships between markers of liver function and the onset of type 2 diabetes.

Materials and Methods: This study was conducted after the approval from institutional ethical committee. Twenty five patients reporting to the OPD of K. S. Hegde Hospital diagnosed for type 2 diabetes between the age group of 40-50 years of both sex and 25 healthy age and sex matched individuals were included in the study. Under aseptic precautions blood samples were collected and centrifuged to get serum and was used for estimation. Data were expressed as the mean $\pm S D$. Spearman's correlation coefficients were calculated to evaluate the relationship between serum glucose and liver function enzymes.
\end{abstract}

Result: The results of the present showed that the ALT, AST and GGT levels in Type 2 Diabetic patients was increased significantly $(p<0.01)$ as compared to normal controls.

Conclusion: In this study, we found an association between the level of liver enzymes, ALT, AST and GGT in type 2 diabetes. Thus these liver enzyme levels can be used as a biomarker for the assessment of type 2 diabetes.

Keywords : Aspartate Aminotransferase; Alanine Aminotransferase; Gamma-Glutamyl Transpeptidase;

\section{Introduction:}

Type 2 diabetic individuals are at higher risks of liver function test abnormalities than individuals who do not have diabetes. Subtle chronic elevations of transaminases often reflect underlying insulin resistance. Elevation of transaminases within three times the upper limits of normal is not a contraindication for starting oral

Access this article online Quick Response Code

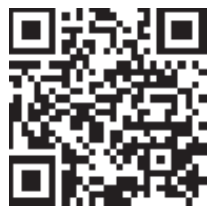
antidiabetic or lipid modifying therapy. In contrast, antidiabetic agents have been shown to decrease alanine aminotransferase levels as tighter blood glucose levels are attained.
Change in liver function tests is considered as surrogate marker of liver injury and non-alcoholic fatty liver disease (NAFLD) [4]. Previous studies have indicated that circulating concentration of liver function tests like gamma-glutamyltransferase (GGT), alanine aminotransferase (ALT) and aspartate aminotransferase (AST) are increased in individuals with insulin resistance and the metabolic syndrome[2,4,5]. In addition, these components of liver function tests have been shown to be positively correlated with the risk of future type 2 diabetes $[4,6]$. A recent meta-analysis on this topic showed that both elevated ALT and GGT were associated with increased risk of diabetes, while GGT might be a stronger risk factor than ALT[6]. 
Chronic mild elevation of transaminases are frequently found in type 2 diabetic patients. Increased activities of liver enzymes such as aspartate aminotransferase (AST), alanine aminotransferase (ALT), and $\gamma$-glutamyl transpeptidase (GGT) are indicators of hepatocellular injury. Increased activity of these markers is associated with insulin resistance[1], metabolic syndrome, and type 2 diabetes.

The liver helps maintain normal blood glucose concentration both in the fasting and postprandial states. Glycogenolysis and an increase in hepatic glucose production is seen due to loss of insulin effect on the liver. Abnormalities of triglyceride storage and lipolysis in insulin-sensitive tissues such as the liver are an early manifestation of conditions characterized by insulin resistance and are detectable earlier than fasting hyperglycemia. The genetic, environmental, and metabolic factors and sequence of events that lead to the underlying insulin resistance, however, is not fully understood[7].

Hyperinsulinemia might directly lead to hepatic insulin resistance with related fatty changes. The excess in free fatty acids found in the insulin-resistant state is known to be precisely toxic to hepatocytes. Putative mechanisms include cell membrane disruption at high concentration, mitochondrial dysfunction, toxin formation, and activation and inhibition of key steps in the regulation of metabolism[9]. Other potential explanations for elevated transaminases in insulin-resistant states include oxidant stress from reactive lipid peroxidation, peroxisomal betaoxidation, and recruited inflammatory cells. The insulinresistant state is also marked by an increase in proinflammatory cytokines such as tumour necrosis factor$\alpha$ (TNF- $\alpha$ ), which may also contribute to hepatocellular injury. In preliminary studies, an increased frequency of specific TNF- $\alpha$-promoter polymorphism was found in nonalcoholic steatohepatitis (NASH) patients, suggesting a possible genetic link or predisposition to fatty liver found in insulin-resistant states[10].

The above theories all impute elevated transaminase to direct hepatocyte injur 
approximately $5 \mathrm{ml}$ was collected without anticoagulant in appropriate sterile vials by venous arm puncture. The serum was separated by centrifugation at 1500rpm for 15 minutes and stored at $4^{\circ} \mathrm{C}$.

\section{Statistical Analysis:}

Data were expressed as the mean \pm SD. Spearman's correlation coefficients were calculated to evaluate the relationship between serum glucose and liver function enzymes.

\section{Results:}

In the present study, patients reporting to the O.P.D of K.S. Hegde Hospital who were diagnosed for type 2 diabetes between the age group of 40-50 years of either sex and 25 healthy age and sex matched individuals were used. The results showed that, ALT, AST and GGT levels in type 2 diabetic patients was increased significantly $(p<0.01)$ as compared to normal controls (Table-1, Fig-1-4).

The results of ALT, AST and GGT levels had shown that, it was increased significantly $(p \varangle 0.01)$ in type 2 diabetic patients as compared to normal controls (Table-1, Fig-1-4).

\begin{tabular}{|l|l|l|l|}
\hline $\begin{array}{l}\text { Groups } \\
\text { Parameters } \rightarrow\end{array}$ & Normal & Type 2 Diabetes & PValue \\
\cline { 2 - 4 } & & & \\
\hline Glucose (mg/dL) & $105.9 \pm 22.1$ & $171.9 \pm 23.8$ & $\varangle 0.010$ \\
\hline ALT (SGPT) (U/L) & $24.7 \pm 11.7$ & $52.7 \pm 9.0$ & $<0.010$ \\
\hline AST (SGPT) ( U/L) & $24.1 \pm 11.5$ & $51.7 \pm 12.8$ & $<0.010$ \\
\hline GGT (IU/L) & $26.6 \pm 13.9$ & $52.9 \pm 7.1$ & $<0.010$ \\
\hline
\end{tabular}

Table-1: The level of Glucose, ALT, AST and GGT in Normal individuals and Type 2 Diabetic patients. Values are expressed as M ean \pm Standard Deviation. $N=25$ in each group.

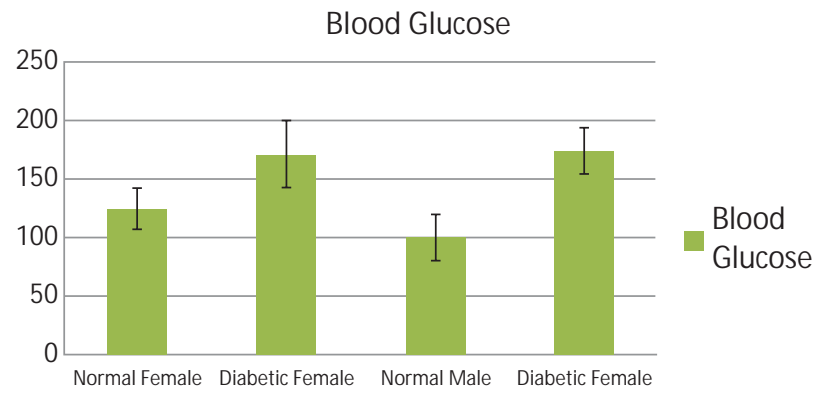

Fig-1: The Blood Glucose level in Normal individuals and Diabetic patients. $\mathrm{N}=25$ in each group. The Glucose level was increased significantly $(\mathrm{p} \varangle 0.01)$ in Diabetic patients as compared to normal controls.

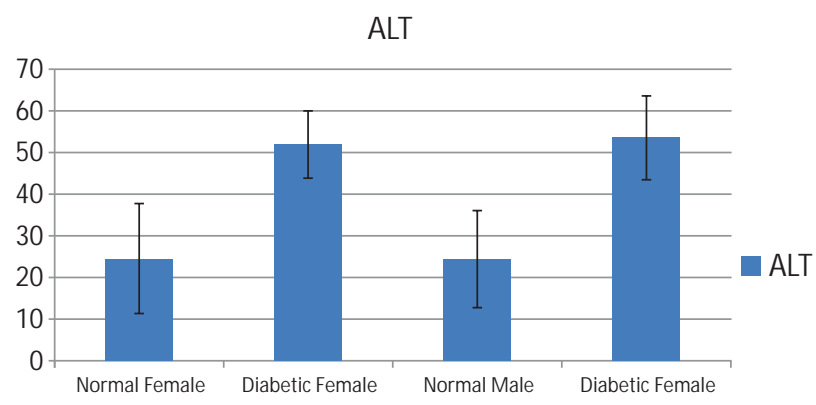

Fig-2: The ALT level in Normal individuals and Diabetic patients. $\mathrm{N}=25$ in each group. The ALT level was increased significantly $(\varangle 0.01)$ in Diabetic patients as compared to normal controls.

\section{AST}

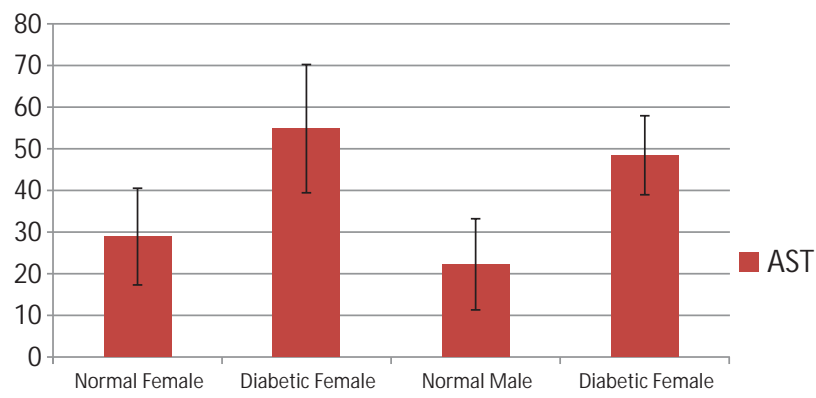

Fig-3: The AST level in Normal individuals and Diabetic patients. $\mathrm{N}=25$ in each group. The AST level was increased significantly $(<0.01)$ in Diabetic patients as compared to normal controls.

\section{GGT}

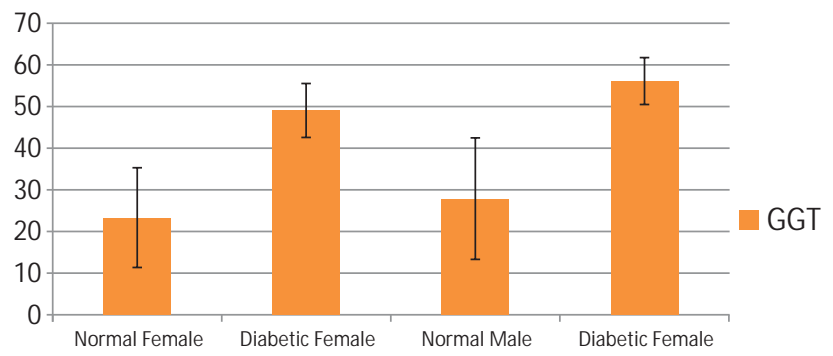

Fig-4: The GGT level in Normal individuals and Diabetic patients. $\mathrm{N}=25$ in each group. The GGT level was increased significantly $(<0.01)$ in Diabetic patients as compared to normal controls.

\section{Discussion:}

Type 2 Diabetes is associated with increased BMI (Body Mass Index) due to sedentary lifestyle and increased processed food intake. Type 2 diabetes is commonly found in middle aged individuals.

Type 2 diabetes comprises about $80 \%$ cases of diabetes mellitus. Diabetes is a leading cause of morbidity and mortality world over. It is estimated that approximately $1 \%$ of the population suffers from diabetes mellitus. The incidence is rising in the developed countries of the world at the rate of about $10 \%$ per year, especially of type 2 
diabetes, due to rising incidence of obesity and reduced activity level. Diabetes mellitus is expected to continue as a major health problem owing to its serious complications, especially end stage renal disease, IHD, gangrene of the lower extremities, and blindness in the adults [17].

This was evidenced in the previous studies and in our present study, in which we observed a significant increase in the level of ALT, AST and GGT. The increase in the liver enzymes recorded in the present study clearly indicates the onset of type 2 diabetes.

The major metabolic defect in type 2 diabetes is either a delayed insulin secretion relative to glucose load (impaired insulin secretion), or the peripheral tissues are unable to respond to insulin (insulin resistance). Type 2 diabetes is a heterogenous disorder with a more complex etiology and is far more common than type 1 , but much less is known about its pathogenesis. In type 2 diabetes, there is nonenzymatic glycosylation of proteins which produces advanced glycosylated end products that gets deposited in the basement membranes of blood vessels and other

\section{References:}

1. Marchesini G, Brizi M, Bianchi G, Tomassetti S, Bugianesi E, Lenzi M, McCullough AJ, Natale S, Forlani G, M elchionda N: Nonalcoholic fatty liver disease: a feature of the metabolic syndrome. Diabetes , 2001:50:1844-1850.

2. Wannamethee SG, Shaper AG, Lennon L, Whincup PH: Hepatic enzymes, the metabolic syndrome, and the risk of type 2 diabetes in older men. Diabetes Care, 2005; 28: 2913-2918.

3. Perry IJ, Wannamethee SG, Shaper AG: Prospective study of serumglutamyltransferase and risk of NIDDM. Diabetes Care, 1998; 21:732-737.

4. Hanley AJ, Williams K, Festa A, Wagenknecht LE, D'Agostino RB Jr, (2004) Elevations in markers of liver injury and risk of type 2 diabetes: the insulin resistance atherosclerosis study. Diabetes53: 2623-2632.

5. Nakanishi N, Suzuki K, Tatara K (2004) Serum gammaglutamyltransferase and risk of metabolic syndrome and type 2 diabetes in middle-aged Japanese men. Diabetes Care 27: 1427-1432.

6. Fraser A, Harris R, Sattar N, Ebrahim S, Davey Smith G,. (2009) Alanine aminotransferase, gamma-glutamyltransferase, and incident diabetes: the British Women's Heart and Health Study and metaanalysis. Diabetes Care 32: 741-750.

7. Lewis GF, Carpentier A, Khosrow A, Giacca A: Disordered fat storage and mobilization in the pathogenesis of insulin resistance and type 2 diabetes.Endocr Rev 23: 201-229,2002

8. Shimomura I, Matsuda M, Hammer RE, Bashmakov Y, Brown MS Goldstein JL: Decreased IRS-2 and increased SREBP-1C lead to mixed insulin resistance and sensitivity in livers of lipodystrophic and ab/ab mice.Mol Cell6 : 77-86,2000

9. Neuschwander-TetriBA, Caldwell S: Nonalcoholic steatohepatitis: summary of AASLD single topic conference. Hepatology37 : 12021219,2003 structures.

However, in this study we tried to exclude the confounding variables and results obtained can be taken as the standard normal in our environment.

\section{Conclusion:}

In the present study, a significant increase in the level of liver enzymes, ALT, AST and GGT was observed in type 2 diabetic patients when compared to the normal patients.

Hence, we found an association between the level of liver enzymes, ALT, AST and GGT in type 2 diabetic patients. Thus these liver enzymes can be used as a biomarker for the assessment of type 2 diabetes.

With a thorough study about the level of liver enzymes, it is possible to monitor complications of type 2 diabetes.

\section{Acknowledgement:}

This research was supported financially by Indian Council of M edical Research as STSfellowship.

Conflict of fellowship: None declared

10. Grove J, Daly AK, Bassendine MF, Day CP: Association of a tumor necrosis factor promoter polymorphism with susceptibility to alcoholic steatohepatitis. Hepatology 26:143-146, 1997

11. O'Brien RM, Granner DK: Regulation of gene expression by insulin.Biochem 278: 609-619,1991

12. Wannamethee G, Ebrahim S, Shaper AG: Gamma glutamyltransferase: determinants and associations with mortality from ischaemic heart disease and all causes. Am J Epidemiol 42:699. 708,1995

13. Sattar N, Scherbakova O, Ford I, O'Reilly DS, Stanley A, Forrest E, M acfarlane PW, Packard CI, Cobbe SM, Shepherd J: Elevated alanine aminotransferase predicts new onset type 2 diabetes independently of classical risk factors, metabolic syndrome, and C-reactive protein in the West of Scotland Coronary Prevention Study. Diabetes 53:2855-2860, 2004

14. Vozarova B, Stefan N, Lindsay RS, Saremi A, Pratley RE, Bogardus C, Tataranni PA: High alanine aminotransferase is associated with decreased hepatic insulin sensitivity and predicts the development of type 2 diabetes. Diabetes 51:1889-1895, 2002

15. Nannipieri M, Gonzales C, Baldi S, Posadas R, Williams K, Haffner SM Stern MP, Ferrannini E: Liver enzymes, the metabolic syndrome, and incident diabetes: the Mexico City Diabetes Study. Diabetes Care 28:1757-1762, 2005

16. Hanley AJ, Williams K, Festa A, Wagenknecht LE, D'Agostino RB Jr Haffner SM: Liver markers and development of the metabolic syndrome: the insulin resistance atherosclerosis study. Diabetes 54: 3140-3147, 2005

17. Harsh M ohan: Textbook of Pathology, Sixth Edition: 2010 ISBN: $978-$ 81-8448-702-2 